\title{
Qualidade do leite cru refrigerado destinado a beneficiamento na cidade de Volta Redonda-RJ e região
}

\section{Quality of refrigerated raw milk intended to processing in Volta Redonda- $R J$ and nearby region}

\author{
1 Thaís Rodrigues Ferreira \\ 2 Denise Celeste Godoy de Andrade Rodrigues denise.cgar@gmail.com
}

1 Centro Universitário de Volta Redonda - UniFOA
2 Universidade do Estado do Rio de Janeiro - UERJ; Centro Universitário de Volta Redonda - UniFOA

\section{Resumo}

O leite é um alimento rico em nutrientes, como proteínas, carboidratos, vitaminas, gorduras e sais. É considerado um excelente meio de cultura para crescimento de micro-organismos que podem ser deteriorantes e/ ou potencialmente patogênicos. Por ser um alimento amplamente consumido, faz-se necessário estudo da contaminação do leite. 0 trabalho objetivou quantificar a presença de micro-organismos e células somáticas e verificar a presença de resíduos de antibiótico no leite cru refrigerado. Foram analisadas 29 amostras oriundas de fazendas de Volta Redonda-RJ e região, empregando-se Contagem Bacteriana Total (CBT) e Contagem de Células Somáticas (CCS) pelo método de Citometria de Fluxo. A Análise de Resíduo de Antibiótico (ATB) foi realizada com o Kit Delvo Test. Apenas $2(6,9 \%)$ amostras estavam dentro do esperado nos três requisitos, indicando que são necessárias práticas mais eficazes de higienização em todas as partes do processo de ordenha.

\section{Palavras-chave}

Microbiologia de Alimentos. Contagem de células. Antibacterianos.

\begin{abstract}
Milk is a food rich in nutrients, such as proteins, carbohydrates, vitamins, fats and salts. It is considered an excellent culture medium for the growth of microorganisms, which can be deteriorating and / or potentially pathogenic. As it is a widely consumed food, it is necessary to study the contamination of milk. The work aimed to quantify the presence of microorganisms and somatic cells and to verify the presence of antibiotic residues in refrigerated raw milk. Twenty-nine samples from farms in Volta Redonda$R J$ and region were analyzed using Total Bacterial Count (TBC) and Somatic Cell Count (SCC) by the Flow Cytometry method. Antibiotic Residue Analysis (ARA) was performed with the Delvo Test Kit. Only 2 (6.9\%) samples were as expected in the three requirements, indicating that more effective hygiene practices are needed in all parts of the milking process.
\end{abstract}

\section{Keywords}

Food Microbiology. Cell counts. Antibiotics.

\section{Como você deve citar?}

FERREIRA, Thaís Rodrigues; RODRIGUES, Denise Celeste Godoy de Andrade. Qualidade do leite cru refrigerado destinado a beneficiamento na cidade de Volta Redonda-RJ e região. Cadernos UniFOA, Volta Redonda, n. 42, p. 33-39, abril, 2020. 


\section{INTRODUÇÃO}

Micro-organismos são formas de vida microscópicas e unicelulares, impossíveis de se ver a olho nu, que podem ser encontrados em todos os ambientes (terrestres e aquáticos) e afetam todas as formas de vida. 0 grupo dos micro-organismos inclui bactérias, protozoários, fungos, microalgas e vírus (MADIGAN et al., 2010).

Apesar de serem as menores formas de vida, constituem a maior massa de matéria viva do planeta, sendo que a maioria contribui positivamente na manutenção do equilíbrio dos organismos vivos e dos elementos químicos no nosso ambiente. Muitos também possuem grande valor comercial, sendo usados desde a síntese de produtos químicos até a produção de alimentos (MADIGAN et al., 2010). Alguns, porém, causam doenças e, por isso, são considerados patogênicos.

Em relação aos micro-organismos encontrados no leite in natura, pode-se encontrar os benéficos e os patógenos. Entre as diversas bactérias que podem ser encontradas no leite, destacam-se as da família Enterobacteriaceae e dos gêneros Alcaligenes, Bacillus, Corynebacterium, Staphylococcus, Streptococcus, Leuconostoc, Listeria e Pseudomonas (BUENO et al., 2008), que, quando encontrados, são indicativos de contaminação, visto que, em animais sadios, a microbiota é composta por micro-organismos benéficos, como os lactobacilos e lactococos (HOFFMANN, 1994).

De acordo com o Art. 475 do Decreto 30.691, "entende-se por leite, sem outra especificação, o produto oriundo da ordenha completa, ininterrupta, em condições de higiene, de vacas sadias, bem alimentadas e descansadas". O leite é um alimento rico em nutrientes, como proteínas, carboidratos, vitaminas, gorduras e sais minerais (SANTOS; FONSECA, 2001). Por essa característica, se constitui um excelente meio de cultura para crescimento de micro-organismos que podem ser deteriorantes e/ou potencialmente patogênicos. Os deteriorantes degradam o leite, diminuindo sua qualidade, causando importante perda econômica para os produtores (GUERREIRO et al., 2005; BERSOT et al., 2010). Já os patogênicos, apresentam um grande risco à saúde pública, visto que o leite é um alimento amplamente consumido.

Segundo a Instrução Normativa 62 (IN 62) (BRASIL, 2011), os limites máximos para presença de micro-organismos no leite cru refrigerado são de $100.000 \mathrm{UFC} / \mathrm{mL}$, enquanto os limites para Células Somáticas são de 400.000 células $/ \mathrm{mL}$. Essa mesma IN estabelece que o leite deve ser analisado, pelo menos uma vez por mês, em laboratórios credenciados na Rede Brasileira de Laboratórios de Controle de Qualidade do Leite (RBQL), para o monitoramento de sua qualidade, podendo, assim, o Ministério da Agricultura, Pecuária e Abastecimento (MAPA) acompanhar a qualidade do leite de cada propriedade rural.

0 estudo dos grupos de micro-organismos pode indicar a fonte da contaminação. Após ser secretado no úbere, o leite pode ser contaminado a partir de três fontes principais: dentro da glândula mamária, na superfície exterior do úbere e tetas e na superfície dos equipamentos utilizados na ordenha e armazenamento (SANTOS; FONSECA, 2001). O Staphylococcus aureus é o maior agente causador da mastite, que é uma inflamação nas glândulas mamárias. Quando presente no leite, indica uma contaminação por mastite. Os coliformes totais indicam contaminação ambiental, enquanto a Escherichia coli aponta para contaminação fecal. Determinar a intensidade da contaminação em cada ponto da ordenha é importante para adoção de medidas de controle mais efetivas (SILVA et al., 2011).

A presença de células somáticas no leite é um indicativo de mastite, principal afecção do gado leiteiro com alta prevalência em muitas propriedades rurais do país (LANGONI et.al., 2011). A partir da contagem dessas células, é possível quantificar o grau da infecção. 
Outras substâncias que podem ser frequentemente encontradas no leite são resíduos de antibióticos. A principal fonte dessa contaminação é o uso desse medicamento no tratamento da mastite. 0 consumo de leite contendo essas substâncias podem causar problemas, como hipersensibilidade, podendo levar à choque anafilático em indivíduos sensíveis a essa substância; seleção de cepas bacterianas resistentes, tanto no consumidor quanto no ambiente; desequilíbrio da microbiota intestinal e até efeito teratogênico (NERO et al., 2007). A presença de antibiótico no leite o torna impróprio para uso tanto na indústria quanto para consumo humano, uma vez que não existem tratamentos tecnológicos capazes de inativar tais substâncias (SANTOS, 2003 apud MENDES; SAKAMOTO; LEITE, 2008).

De acordo com Bueno et al. (2004), pesquisas feitas no Brasil indicam que, de maneira geral, o leite apresenta más condições higiênico-sanitárias, sendo encontrados altos níveis de contagem microbianas. Esse quadro é um importante problema de saúde pública, principalmente, se o leite for consumido cru, sem um tratamento adequado (BELOTI et al., 1999; NERO et al., 2005; BUENO et al., 2008; MATTOS et al., 2010).

Grande parte da população brasileira consome leite em sua dieta diária. Com a produção aumentada, muitos produtores não zelam pela higienização adequada durante o processo de ordenha e armazenamento, pondo em risco a saúde dos consumidores. Por esse motivo, mostra-se importante o estudo sobre a contaminação do leite cru destinado para beneficiamento. Diante do exposto, o presente trabalho teve como objetivo quantificar a presença de micro-organismos e evidenciar a presença de antibiótico no leite cru comercializado na cidade de Volta Redonda-RJ.

\section{MATERIAIS E MÉTODOS}

\subsection{Coleta das Amostras}

Foram coletadas 29 amostras, de 29 fazendas distintas. As amostras foram coletadas do tanque de expansão (tanque de refrigeração de leite), com auxílio de uma concha própria para coleta, previamente esterilizada em autoclave a $121{ }^{\circ} \mathrm{C}$ por $20 \mathrm{~min}$. $\mathrm{O}$ leite foi homogeneizado por 5 minutos com agitador próprio do tanque. Foram coletados, aproximadamente, $100 \mathrm{~mL}$ de leite, colocado em potes estéreis. $O$ leite foi mantido sobre refrigeração a $5^{\circ} \mathrm{C}$, em caixa isotérmica (isopor), com gelo reciclável e, assim, enviadas ao laboratório, mantendo-se conservadas até chegar ao local. As análises foram feitas no laboratório Clínica do Leite, situado em Piracicaba-SP, credenciado pelo MAPA para realizar ACQL (BRASIL, 2008).

\subsection{Análises}

Foram realizados testes de Contagem Bacteriana Total (CBT), Contagem de Células Somáticas (CCS) e Análise de Resíduo de Antibiótico (ATB).

As análises de CBT e CCS foram feitas pelo método de Citometria de Fluxo, seguindo Norma Internacional ISO (ISO 16297:2013/IDF161:2013 e ISO 13366-2:2006/IDF148-2:2006, respectivamente). Os testes de Resíduo de Antibiótico foram feitos com o Kit Delvo Test, seguindo as recomendações do fabricante. 


\section{RESULTADOS E DISCUSSÃO}

Na Tabela 1, são apresentados os resultados das análises realizadas. Pode-se observar que, das 29 amostras analisadas, apenas $6,9 \%(n=2)$ estavam dentro do padrão nas três categorias analisadas. No que se refere à CCS, apenas $24,1 \%(n=7)$ estavam dentro dos limites estabelecidos, e $17,5 \%(n=5)$ estavam dentro dos parâmetros para CBT. Todas as 29 amostras obtiveram resultado negativo quanto à presença de resíduos de antibiótico, entretanto, $75,6 \%(n=22)$ das amostras estão com CCS com qualidade abaixo do esperado, e $82,8 \%(n=24)$, com CBT abaixo do padrão.

Tabela 1 - Resultado das Análises

\begin{tabular}{|c|c|c|c|}
\hline Amostra & $\operatorname{CCS}(\mathrm{mil} / \mathrm{mL})$ & CBT (mil UFC/mL) & ATB \\
\hline 1 & $181 *$ & 136 & NEG \\
\hline 2 & 1589 & 472 & NEG \\
\hline 3 & 3012 & 3964 & NEG \\
\hline 4 & 548 & 216 & NEG \\
\hline 5 & 652 & 715 & NEG \\
\hline 6 & 1824 & 329 & NEG \\
\hline 7 & $26 *$ & 8* & NEG \\
\hline 8 & 1843 & 264 & NEG \\
\hline 9 & 1075 & 507 & NEG \\
\hline 10 & 731 & 747 & NEG \\
\hline 11 & 850 & 4024 & NEG \\
\hline 12 & $265 *$ & 763 & NEG \\
\hline 13 & 832 & 6673 & NEG \\
\hline 14 & 524 & 1060 & NEG \\
\hline 15 & $183^{*}$ & 655 & NEG \\
\hline 16 & 531 & 762 & NEG \\
\hline 17 & $314 *$ & 89* & NEG \\
\hline 18 & 596 & 3178 & NEG \\
\hline 19 & 575 & 1001 & NEG \\
\hline 20 & 956 & $37 *$ & NEG \\
\hline 21 & $301 *$ & 155 & NEG \\
\hline 22 & 640 & 919 & NEG \\
\hline 23 & 438 & 570 & NEG \\
\hline 24 & 517 & 9* & NEG \\
\hline 25 & $339 *$ & 204 & NEG \\
\hline 26 & 2190 & 342 & NEG \\
\hline 27 & 754 & $73^{*}$ & NEG \\
\hline 28 & 641 & 449 & NEG \\
\hline 29 & 747 & 1983 & $\mathrm{NEG}$ \\
\hline
\end{tabular}

(*) Valores dentro do padrão.

Fonte: autores, 2018.

Os valores de células somáticas variaram de 26.000 a 3.012 .000 células $/ \mathrm{mL}$, com média de 816.000 células/mL. Isso indica alto índice de infecção mamária, visto que, na mastite, a resposta inflamatória faz com que os vasos sanguíneos se dilatem, para que as células de defesa migrem para o tecido doente. Juntamente com essas células, outras substâncias presentes no sangue também migram para o leite, tais como, íons cloro e sódio, fazendo com que o leite adquira um sabor salgado, além de enzimas que 
podem causar alterações na gordura e proteína (BRITO; BRITO, 2001). Oliveira (2013) relacionou altas taxas de CCS do tanque de leite à presença de patógenos contagiosos no rebanho.

Além de ser importante fonte de contaminação, a mastite também pode causar alterações na composição do leite e alterar a habilidade de síntese do tecido secretor, seja pela ação direta dos patógenos ou por enzimas secretadas no interior das glândulas (MACHADO; PEREIRA; SARRÍES, 2000; SANTOS, 2002). Rangel et al. (2009) relataram uma correlação entre a contagem de células somáticas e o teor de gordura, de extrato seco desengordurado e de lactose. Dessa forma, quando a CCS está aumentada, aumenta-se também os teores dessas características, comprovando a alteração de qualidade que altas taxas de células somáticas podem ocasionar. Todas essas alterações acabam por afetar a produção de produtos lácteos.

Os valores de CBT variaram de 8.000 a 6.673.000 UFC/mL, com média de $1.045 .000 \mathrm{UFC} / \mathrm{mL}$, evidenciando a baixa qualidade dos leites analisados. A contaminação microbiana prejudica a qualidade do leite, reduz o tempo de prateleira do leite e seus derivados e pode ser altamente prejudicial para a saúde do consumidor (MOTTA et al., 2015).

Taffarel et al. (2013) encontraram diferença de CBT entre diferentes tipos de ordenha, sendo a ordenha canalizada o método com menor índice de contaminação. Isso ocorre pelo fato de o equipamento possuir um sistema de limpeza, com circulação de água quente e injeção de ar. Essa maior facilidade de higienização pode ter contribuído para o baixo valor de CBT e, consequentemente, menor contaminação. Desse modo, pode-se perceber a importância de práticas de higienização. Comparando os valores encontrados pelos autores com uma média de $259.000 \mathrm{UFC} / \mathrm{mL}$, o resultado ficou muito abaixo da média aqui encontrada (1.045.000 UFC/mL)

Vargas et al. (2013) relacionaram a alta taxa de CBT com a redução significativa do teor de lactose e sólidos não gordurosos e, ao mesmo tempo, houve aumento nas concentrações de gordura, proteína, minerais e sólidos totais. Juntamente com essa alteração, há um aumento de células somáticas, evidenciando um processo inflamatório. Bueno et al. (2008) também encontraram relação com as variáveis gordura, proteína e lactose.

Eckstein et al. (2014) encontraram valores abaixo do resultado descritos no presente trabalho, sendo a média para CCS de 718,56 células/mL, enquanto a média de CBT foi de $233.000 \mathrm{UFC} / \mathrm{mL}$.

A contaminação do leite pode ser significantemente diminuída com a adoção de técnicas profiláticas, como limpeza de utensílios e equipamentos, higiene dos operadores e ordenhadores, controle do ambiente onde ocorre a ordenha e manejo dos animais. A água utilizada para toda higienização deve ser potável, pois de outra maneira pode se tornar fonte de contaminação (GUERREIRO et al., 2005). Segundo Santos (2002), a técnica de preparação do úbere antes da ordenha também tem efeito positivo sobre a ocorrência de novas infecções mamárias.

Nunes e D'Angelino (2007) testaram para presença de antibiótico em amostras de leite provenientes de fazendas produtoras de leite e também leite pronto para consumo. Encontraram resultado positivo em 10\% das amostras, sendo uma delas no leite pronto para consumo. Analisando amostras de leite cru vendido de forma clandestina, Nero et al. (2004) evidenciaram a presença de antibiótico em 11,5\% ( $n=24)$ das amostras e evidenciaram também a presença de inseticidas em mais de $70 \%$ das amostras, alertando para o perigo de consumir leite de origem duvidosa. Nesse trabalho, não foi encontrado nenhum resíduo de antibiótico nas amostras testadas.

Em comparação com os resultados encontrados nos trabalhos aqui citados, evidencia-se a má qualidade higiênico-sanitária das amostras de leite testadas, uma vez que os valores encontrados estão bem acima dos relatados. 


\section{CONCLUSÃO}

O leite cru refrigerado apresentou qualidade ruim em relação à presença de bactérias e células somáticas. As altas contagens encontradas podem ser devido à existência de falha na higienização em qualquer fase do processo, seja no momento da ordenha, no armazenamento ou no transporte. A adoção de medidas profiláticas eficazes, como uma adequada higienização dos materiais utilizados em todo o processo, bem também como higienização de todos os envolvidos com a ordenha, e a adoção de uma postura adequada poderia diminuir significativamente o nível de contaminação, diminuindo também os níveis de células somáticas. Os resultados negativos quanto à presença de antibiótico no leite cru pode ser reflexo de um controle adequado, respeitando-se o tempo de carência indicado em cada medicamento.

\section{REFERÊNCIAS}

BELOTI, V. et al. Avaliação da qualidade do leite cru comercializado em Cornélio Procópio, Paraná. Controle do consumo e da comercialização. Semina: Ciências Agrárias, v. 20, n. 1, p. 12-15, 1999.

BERSOT, L. S. et al. Raw Milk Trade: Profile of the Consumers and Microbiological and Physicochemical Characterization of the Product in Palotina-PR Region. Revista do Instituto de Laticínios Cândido Tostes, Juiz de Fora, n. 373, p. 3-8, 2010.

BRASIL. Decreto 30.691 de 29 de março de 1952. Disponível em: http://presrepublica.jusbrasil.com.br/ legislacao/129097/decreto-30691-52. Acesso em: 20 fev. 2019

BRASIL, Ministério da Agricultura, Pecuária e Abastecimento. Portaria No 197, de 19 de Novembro de 2008. Disponível em: http://www.agricultura.gov.br/arq_editor/file/Aniamal/esco\%20lab\%20clin\%20do\%20leite\%20 esalq.pdf. Acesso em: 22 fev. 2019.

BRASIL, Ministério da Agricultura, Pecuária e Abastecimento. Instrução Normativa nº 62 - Alteração do caput da Instrução Normativa MAPA n 51, de 18 de setembro de 2002. Diário Oficial da União, Brasília, n.432, Seção 1 - Anexo I, p. 14, 2011.

BRITO, M. A. V. P.; BRITO, J. R. F. Qualidade do Leite. In: Produção de Leite e Sociedade: uma análise critica da cadeia do leite no Brasil. Belo Horizonte: FEPMVZ, 2001. p. 61-74

BUENO, V. F. F. et al. Contagem bacteriana total do leite: relação com a composição centesimal e período do ano no Estado de Goiás. Revista Brasileira de Ciência Veterinária, v. 15, n. 1, p. 40-44, jan./abr. 2008.

ECKSTEIN, I. I. et al. Qualidade do leite e sua correlação com técnicas de manejo de ordenha. Scientia Agraria Paranaensis, v. 13, n. 2, p.143-151, 2014. Disponível em: http://e-revista.unioeste.br/index.php/scien\%20tiaagraria/ article/view/7071/7396. Acesso em 29 fev. 2020.

GUERREIRO, P. K. et al. Qualidade Microbiológica de Leite em Função de Técnicas Profiláticas no Manejo de Produção. Ciência e Agrotecnologia, v. 29, n. 1, p. 216-222, jan./fev. 2005.

HOFFMANN, F. L.; CRUZ, C. H. G.; VINTURIM, T. M. Avaliação das Caracteristicas Microbiológicas do Leite Tipo "C" Vendido na Região de São José do Rio Preto-SP. Boletim do Centro de Pesquisa de Processamento de Alimentos, v. 12, n. 1, p. 17-24 1994.

LANGONI, H. et. al. Aspectos microbiológicos e de qualidade do leite bovino. Pesquisa Veterinária Brasileira, v. 31, n. 12, p. 1059-1065, 2011. 
MACHADO, P. F.; PEREIRA, A. R.; SARRÍES, G. A. Composição do leite de tanques de rebanhos brasileiros distribuídos segundo sua contagem de células somáticas. Revista Brasileira de Zootecnia, v. 29, n. 6, p. 1883-1886, 2000.

MADIGAN, M. T. et al. Microbiologia de Brock. 12. ed., editora Artmed. Porto Alegre, 2010. 1128 p.

MATTOS, M. R. et al. Qualidade do leite cru produzido na região do agreste de Pernambuco, Brasil. Semina: Ciências Agrárias, v. 31, n. 1, p. 173-182, 2010.

MENDES, C. G.; SAKAMOTO, S. M.; SILVA, J. B. A. Pesquisa de resíduos de beta-lactâmicos no leite cru comercializado clandestinamente no município de Mossoró, RN, utilizando o Delvotest SP. Arq Inst Biol, v. 75, n. 1, p. 95-8, 2008.

MOTTA, R. G et al. Indicadores de qualidade e composição de leite informal comercializado na região Sudeste do Estado de São Paulo. Pesq. Vet. Bras., Rio de Janeiro, v. 35, n. 5, p. 417-423, 2015.

NERO, L. A. et al. Leite cru de quatro regiões leiteiras brasileiras: perspectivas de atendimento dos requisitos microbiológicos estabelecidos pela Instrução Normativa 51. Ciência e Tecnologia de Alimentos, v. 25, n. 1, p. 191-195, 2005.

NERO, L. A. et al. Resíduos de antibióticos em leite cru de quatro regiões leiteiras no Brasil. Ciência Tecnologia Alimentar, v. 27, n. 2, p. 391-393, 2007.

OLIVIERA, E. F. Análise espacial da contagem de células somáticas e prevalência de patógenos contagiosos da mastite em rebanhos leiteiros em Minas Gerais, Brasil. Juiz de Fora: UFJF, 2013. 70 f. Dissertação (Mestrado em Ciência e Tecnologia de Leite e Derivados) - Programa de Pós-Graduação em Ciência e Tecnologia do Leite e Derivados, da Universidade Federal de Juiz de Fora, Juiz de Fora, 2013.

RANGEL, A. H. N. et al. Correlação Entre a Contagem de Células Somáticas (CCS) e o Teor de Gordura, Proteína, Lactose e Extrato Seco Desengordurado do Leite. Revista Verde de Agroecologia e Desenvolvimento Sustentável, Mossoró, v. 4, n. 3, p. 57-60, 2009

SANTOS, M. V. Antibióticos: como não deixar resíduos no leite. Balde Branco, n. 460, p. 54-57, 2003

SANTOS, M. V. Efeito da mastite sobre a qualidade do leite e derivados lácteos. In: Congresso panamericano de qualidade do leite e controle da mastite. 2002. p. 179-188.

SANTOS, M. V.; FONSECA, L. F. L. Importância e Efeito de Bactérias Psicotróficas Sobre a Qualidade do Leite. Higiene Alimentar, São Paulo, v. 15, n. 82, p. 13-19, 2001.

SILVA, L. C. C. et al. Rastreamento de Fontes da Contaminação Microbiológica do Leite Cru Durante a Ordenha em Propiedades Leiteiras do Agreste Pernambucano. Semina: Ciências Agrárias, Londrina v. 32, n. 1, p. 267276, jan./mar. 2011.

TAFFAREL, L. E. et al. Contagem Bacteriana Total do Leite em Diferentes Sistemas de Ordenha e de Resfriamento. Arquivos do Instituto Biológico, São Paulo, v. 80, n. 1, p. 7-11, jan./mar. 2013.

VARGAS, D. P. et al. Correlação Entre Contagem Bacteriana Total e Parâmetros de Qualidade do Leite. Revista Brasileira de Ciência Veterinária, São Paulo, v. 20, n. 4, p. 241-247, out./dez. 2013. 